\title{
ASSESSMENT
}

\section{Creating a Biology "Studio" to Promote Undergraduate Research}

Mary Beth Hawkins, Miriam Ferzli, Lisa Paciulli,

North Carolina State University

\begin{abstract}
The Research PackTrack (RP) Program provides authentic research experiences to biology undergraduates in a modified studio environment. In semester 1 , students are introduced to the process of scientific inquiry and discourse in a student-centered active learning environment with upside-down pedagogies. In semester 2 , students work in a dedicated molecular biology studio that includes a research laboratory and adjoining conference room. Students use equipment and techniques specific to their research questions, gaining competence and expertise through experimental troubleshooting based on weekly results. In the conference room, they perform specialized data analyses and interact with research peers and mentors. Survey responses for learning and self-efficacy show significant gains for RP students in factors associated with science as a process and community of practice. Fourteen percent of RP students received state and national awards for projects presented at scientific conferences, and 60 percent found long-term research opportunities after program completion.
\end{abstract}

Keywords: active learning, authentic research, community of practice, constructivism, experiential learning, learning communities, learning spaces, student-centered learning

doi: 10.18833/spur/1/2/10

Academia seems to be adopting what has become standard for successful businesses such as Google and Facebook - that innovative workspaces can promote learning and creativity, especially where undergraduate research is concerned. There is a move to restructure or build flexible learning environments that are multidimensional in their applications for teaching and learning (Tom, Voss, and Scheetz 2008; Lippincott 2009; Taylor 2009; Brooks 2012; Park and Choi 2014). In higher education, one example of this type of learning is called the student-centered, active-learning environment with upside-down pedagogies (SCALE-UP; Beichner and Saul 2003; Beichner et al. 2007). In this classroom space, often called a "studio design," students interact with each other and with the instructor(s), move about, work on computers located at tables for each student, solve problems on whiteboards, and so forth. This approach aligns well with experiential learning theory in which learning is defined as a process of constructing knowledge that involves the interaction of learners with their environments or learning spaces (Kolb 1984). The right kind of space can help students engage intellectually, solve problems quickly, and be more creative.

Art and architecture have long embraced the constructivist, studio approach to learning because of its positive effects on critical thinking skills, learning outcomes, and student confidence (Boyer and Mitgang 1996). However, the life sciences have not traditionally incorporated studio learning into curricula. Although it can be implemented in various ways, a studio learning environment should include social collaboration with peers and mentors, active learning through completion of an individual project or "artifact," and critique of the finished work in some type of public forum. In addition, there should be few or no formal lectures or written exams (Clinton and Reiber 2010).

Howard Hughes Medical Institute funding was received in 2011 to design the Research PackTrack (RP) Program at North Carolina State University (NCSU) according to 
FIGURE 1. The Three Major Spaces of the Biology Studio Model

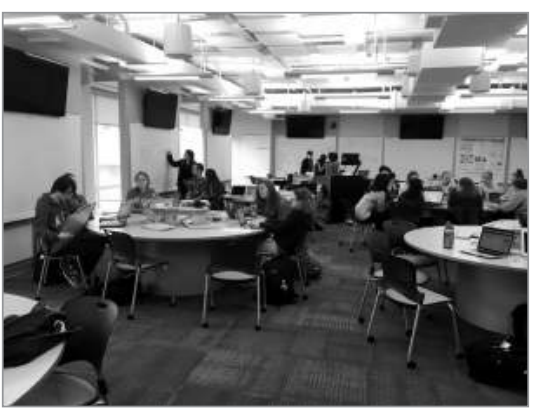

$1 \mathbf{A}$

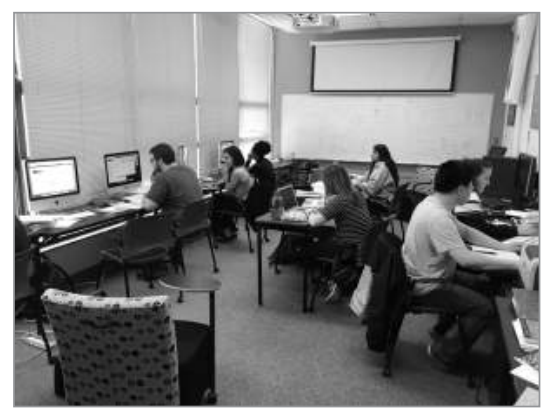

1B

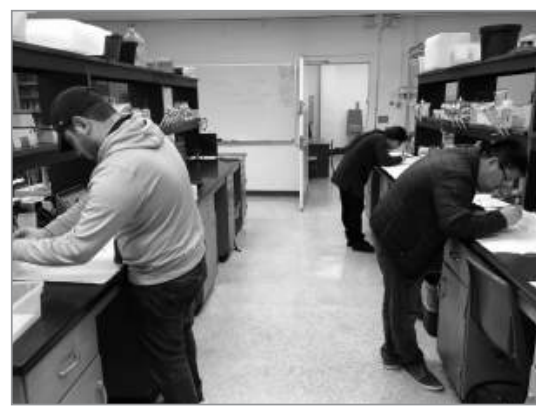

1C

1A: SCALE-UP room for Research I (RI). 1B: Conference room for RI problem sessions and Research II (RII) projects. 1C: Molecular biology laboratory primarily for RII students with visits from RI students during problem sessions.

space and design studio principles. It was understood that students needed a space that would make an authentic research experience possible, even if student numbers were larger than could be accommodated in a faculty member's research laboratory. RP also had to be scalable and sustainable in the long term. Fifty students now enroll in the program each semester and are guided by three faculty members and one graduate or postdoctoral student. RP provides a gateway into the world of scientific research for first- and second-year students in the biological sciences. It creates a community of learners who, through a scaffolded approach, are taught the constructs of the culture of scientific research. This learning community is possible through an innovative way of using and connecting various learning spaces that promotes collaboration. Since construction of knowledge is socially mediated, the RP community has been key for increasing student performance and self-efficacy in science research.

\section{Development of a Biology Studio}

The RP Program is structured as a two-semester course sequence with three interconnected spaces: a SCALE-UP classroom, a conference/problem session room, and a research lab. Students rotate through these spaces during two concurrent semesters to complete tasks that allow them to transition from student to researcher. Since the RP Program caters to first- and second-year students, it was important to structure it in a way that would fit into the first two years of the biological sciences curriculum. The courses are defined as 3-credit electives for the purposes of fitting into the degree but are nontraditional in their approach and structure; they do not have lectures, quizzes, exams, or traditional assessments.

In "Research I" during the first semester, students are introduced to the process of scientific inquiry and discourse in a SCALE-UP classroom. In the SCALE-UP model, students sit at round tables with laptops and work in small groups that are formed according to their research interests. They may work at whiteboards to map out research designs, storyboard, and/or brainstorm (see Figure 1A). In this setting, small- and large-group discussions replace typical lectures, and faculty move around the classroom so that they may best assist students working through various aspects of the research process. In active learning environments such as these, students are given ownership of the learning process by becoming active participants in knowledge construction rather than being passive recipients of information. Students take the lead in this format, and so the level of engagement is very high. Often, students present to each other, discuss issues with each other and with faculty, and can experience trial and error in a safe learning environment.

The Research I course was designed so that all enrolled students would meet together at the beginning of the week in the SCALE-UP room (2 hours) and then again at the end of the week for a 1-hour "problem session" in the RP conference room (3 hours total). For the problem session, students are split into two smaller groups that meet at different times on the same day. During the problem session, they further discuss issues, troubleshoot projects, and/or resolve issues pending from the larger session held earlier in the SCALE-UP room. Interactions between two cohorts of the RP Program can occur during these problem sessions, because they are held in the $\mathrm{RP}$ conference room that is adjacent to the research lab. Such a process encourages incidental meetings between Research I and Research II students, and new students can learn the lab culture through casual conversations with more advanced RP student researchers who are working in the lab as Research II students. In addition, Research I students occasionally step into the laboratory to observe a few simple lab techniques. Thus, more advanced RP students enrolled in Research II become mentors for the incoming cohort taking Research I. By the end of Research I, students have used all three learning spaces, which have served as conduits for interactions between peers and faculty. They have also been initiated into the world of scientific research, complete with attendance at 
an off-campus conference and presentation of their final group project at the university's annual undergraduate research symposium.

In "Research II" during the second semester, students make full use of the studio learning environment, now shifting most of their time to the molecular biology research lab and the adjacent conference room (see Figures $1 \mathrm{~B}$ and 1C). In Research II, students complete biology studio projects that are focused on a few carefully chosen research questions currently pursued by participating faculty. Students design and execute a research project that moves from guided to independent research and, in the process, generates novel data that contribute to faculty research programs. Equipment and supplies are not rotated through the lab as in traditional biology laboratories. Instead, students use the equipment and techniques specific to their research questions. Lab times are highly flexible, vary from week to week, and depend on individual student progress. In the first week of the course, students are required to attend relevant safety workshops as they begin their benchwork with direct supervision by an instructor. Techniques and procedures are first taught to small groups of four to five students in workshops. Instructors schedule the workshops at specific times throughout the week, and students sign up based on their availability using Google Calendar. Once a workshop is completed, students are allowed to work independently on their project with limited scheduling restrictions. However, they must register in advance for lab time via Google Calendar and adhere to benchmark goals prior to advancing in their research. Benchmark goals usually consist of completing a specific set of experiments and meeting with the instructor to discuss the results and next steps. After successful completion of the second course through presentation of their final project at a departmental research symposium, students can transition into research laboratories on campus and in the surrounding scientific community, or expand their initial study in the RP lab through independent study.

\section{Challenges in Space Design and Use}

The main obstacle in space design was addressing the challenges posed by a molecular biology laboratory. Hazardous chemicals require highly regulated usage, storage, and disposal procedures. Operating the sensitive and expensive equipment found in a modern molecular biology lab entails special training prior to use. In addition, campus regulations often limit the ability of students to work unsupervised in a research laboratory. It was critically important to design our space so that it provided an environment of independence and creativity with sufficient supervision to keep students and facilities safe. To deal with these challenges, students move freely between two rooms - the conference room and molecular biology laboratory. The conference room is key to providing the student-centered, creative learning community at the heart of the biology studio concept. Since this room is not designated as a lab, students can have unlimited access without instructor notification or presence, whereas students are not allowed to work in the lab after hours if lab personnel are not present. The overlapping use of laboratory and conference room allows for a fluid transition between deskwork and labwork. Instructors are easily accessible to students in both spaces during the day, and such an arrangement eases the pressure on any required laboratory supervision. The value of the studio format to creative thinking and building community among students is well recognized, as noted by Boyer and Mitgang (1996, xvii): "We are convinced that these studios, scruffy though they may look, are nonetheless models for creative learning that others on campus might well think about." Although the conference room is too small to provide an individual space for each student as in the architecture studios described by Boyer and Mitgang (1996), a flexible room environment has been created through seating and tables that students can rearrange as needed (see Figure 1B). They can also use the permanent projector and whiteboards during their weekly lab meetings, for planning, and for explanation of experimental principles. Also, there are three desktop computers with specialized software for data analyses and four computers for general use. The space includes a microscope with mounted camera and dedicated computer for image capture and data analysis. With this mixed-use model, students working in different research modules are in the space concurrently, which exposes them to different projects and model systems. Student activities vary from day to day and include working individually on processing data, meeting for discussions over lunch or coffee, meeting with faculty, and studying for other classes in between experimental protocols. This setup has been an effective compromise between maintaining conditions for maximum safety and giving the students complete autonomy. The ability to have food and drinks in the conference area makes it a true home base for students, as they can use this space as a calm refuge to rest or recharge day or night.

A few limitations exist on the use of the conference space in addition to a strict "PackTrack students only" policy. Students retain access to this room throughout their years at NCSU, and occasionally alumni stop by to update instructors on their progress, request a letter of reference, or ask questions about research opportunities. For current RP students, this access reinforces the concept that the program is a cohesive and supportive learning community that continues past their time spent in the two core courses.

\section{The Assessment of Learning Gains and Usability}

Over the years, the preprogram and postprogram student perceptions have been assessed through the Classroom Undergraduate Research Experience (CURE) survey (Lopatto 2004), which compares the RP students to a nationwide cohort of undergraduates in research programs. 
For the purposes of this article, preprogram and postprogram comparisons have been included with a two-sample $t$-test of the positive learning and affective gains for the 2011-2015 cohorts of the program $(n=285)$.

Also examined was the amount of time spent by students in the laboratory and conference spaces. To determine the total lab and conference room hours for students in the Gene Expression in the Brain module for the 2015 cohort ( $n=13)$, the students' lab signups on the instructormanaged Google calendar were analyzed. This group was selected because these students must indicate a specific block of time on Google calendar to use specialized equipment, unlike students in other research modules who just post their arrival times. The conference room analysis includes microscope work and instructor meetings but does not include unscheduled free time or the weekly class time of 110 minutes per week.

During the 15-week semester, students spent a total of 633 contact hours in the lab and conference room, with an average of 48.7 contact hours per student. The studio is occupied from 8 a.m. to 8 p.m. throughout the week, with three peaks of greater than 20 contact hours between 12 and 2 p.m. on Tuesdays, 2 and 4 p.m. on Thursdays, and 10 a.m. and 12 p.m. on Fridays (see Figure 2). This pattern of use contrasts sharply with student attendance of traditional labs that run for 2.75 hours once a week (33 total contact hours). In week 12 , a shift occurs from primarily lab use to conference room use, which reflects the progression from experimentation and data collection to data analysis (see Figure 3).

CURE student survey results indicate significant gains in tangible skills such as analyzing data and other information (see Figure 4). Most interestingly, students demonstrate significant gains in factors associated with science as a process and community of practice. These factors include being part of a learning community, understanding how scientists think, understanding of science, readiness for demanding research, understanding the research process, and clarification of a career path. The novel, high-quality work produced by the students in the span of one semester has been recognized with numerous awards. Nine RP students have been selected to present at the National Conferences on Undergraduate Research (NCUR), three have received Sigma Xi Awards for Excellence at the Annual NCSU Undergraduate Research Symposium, and five have won the Derieux Award for Excellence at the North Carolina Academy of Sciences Annual Conference. In addition, research faculty have come to value the RP Program for the quality of its students as well as for its potential to generate meaningful data for their research programs. Sixty percent of RP students have found long-term research opportunities in laboratories throughout NCSU and surrounding institutions. Data on RP student outcomes and CURE survey responses support the idea that innovative FIGURE 2. Daily Timeline of Total Hours Spent in the Biology Studio during a Representative
Semester (Fall 2015)

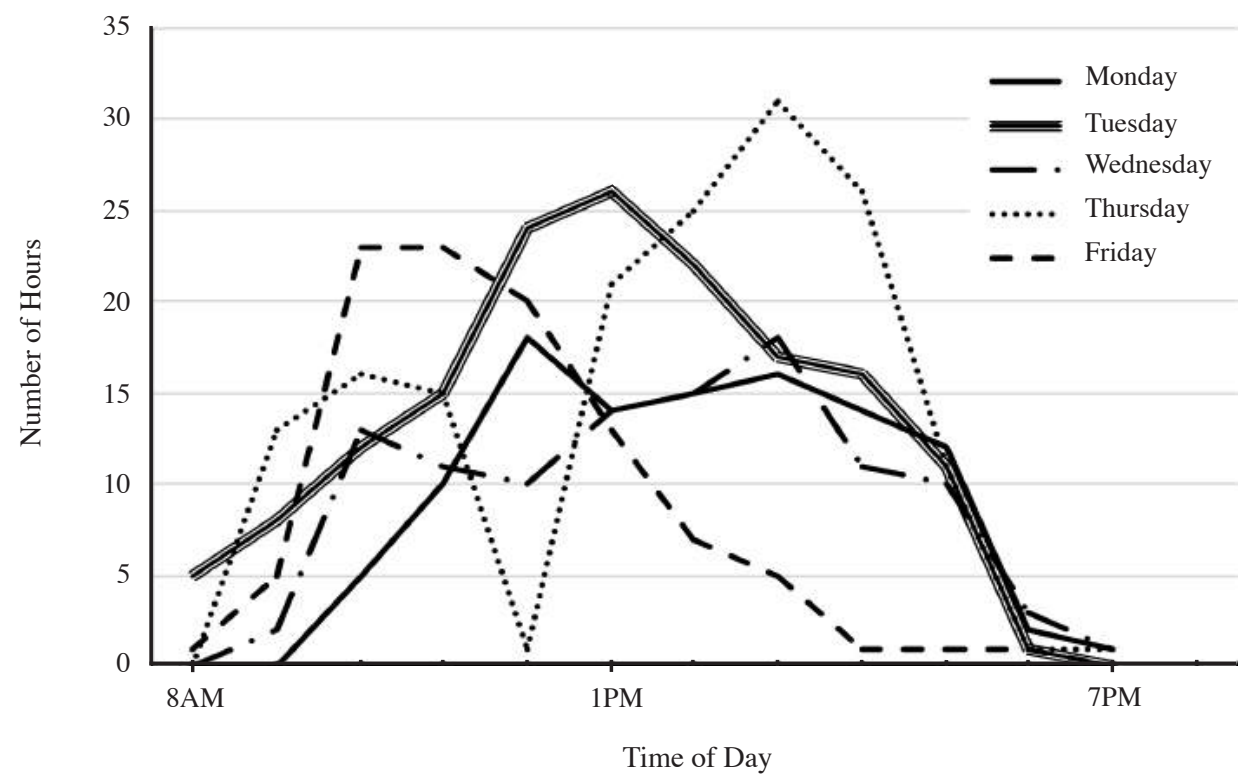

Note: Time on the $\mathrm{X}$-axis indicates the beginning of each 1-hour time block. Lines on the graph represent each day of the week (see legend). The numbers of students occupying the laboratory for each hour block throughout the semester were determined by tabulating all student lab signups in the course Gene Expression in the Brain from the course's Google calendar $(n=13)$. 
FIGURE 3. Total Weekly Hours Spent in the Studio Laboratory or Conference Room (Fall 2015)

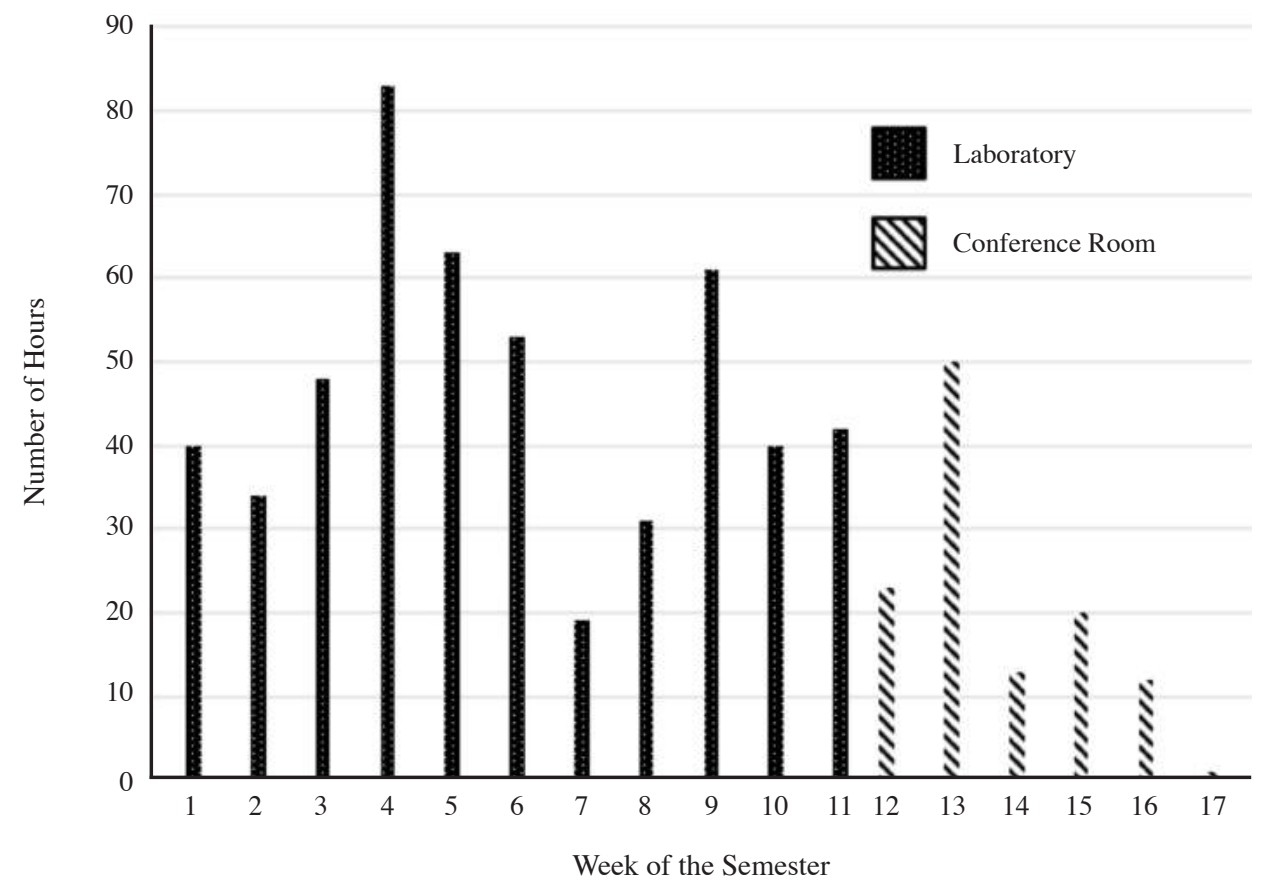

Note: The number of students occupying the laboratory or conference room each week throughout the semester was determined by tabulating all student lab signups in the course Gene Expression in the Brain from the course's Google calendar $(n=13)$. Signups were categorized as either lab or conference room use by the planned activity listed on their Google calendar submissions. Bars indicate the total number of hours of students in the lab (black) or conference room (hatched) per week. The conference-room totals include microscope work and instructor meetings but do not include unscheduled free time or class time.

learning spaces can foster collaboration, boost creativity, and promote successful undergraduate research.

Since the inception of the RP Program in 2011 with a smaller cohort than is currently the case, 125 freshman and sophomores have completed the program and have the following demographics: 24 percent male, 76 percent female, 69 percent Caucasian, 16 percent Asian American, 5 percent Hispanic, 3 percent African American, and 3 percent Other. NCSU's student population is composed of 45 percent women, and the RP Program attracts more female students than average. For the most part, however, RP students are representative of the undergraduate population at NCSU for ethnic groups.

\section{Lessons Learned}

Experiences to date indicate that participation in a community of practice increases student self-confidence and provides a long-lasting sense of belonging that extends beyond the higher education institution. This has been an important point to consider as steps were taken to expand the RP Program. A key to keeping the student learning communities intact is to ensure that cohorts remain together as students progress through the program. Research I and II are now offered in both fall and spring semesters. The original plan was to have two, staggered cohorts moving through the program at once. However, some students chose to skip a semester to add more flexibility to their schedules instead of taking the courses back to back with their original cohort of classmates. This practice started to affect the sense of belonging and relatedness - important markers of motivation in science and future retention in science careers. In addition, the RP program needs to be fully integrated across the curriculum to achieve full success. The two RP courses are a part of the biology degree, but better collaboration is needed with advisers in the biological sciences department as well as in other life science departments to help students understand how the RP courses can fit into their plan of work. Since RP courses are not required, first- and secondyear students often do not know how to allocate time for the program because of the science requirements they must complete during their first two years. Currently, the RP courses count as "major elective" courses, but having multiple designations would add flexibility for students so that they can count these courses for their degree in several ways. One designation under consideration is applying a writing-intensive label to the first RP course because the students write a great deal in that part of the program. Since NCSU's degree programs have writing-intensive course requirements, students would be able to count Research I 
FIGURE 4. Learning and Self-Efficacy Gains of Research PackTrack Students Compared to Other CURE Respondents

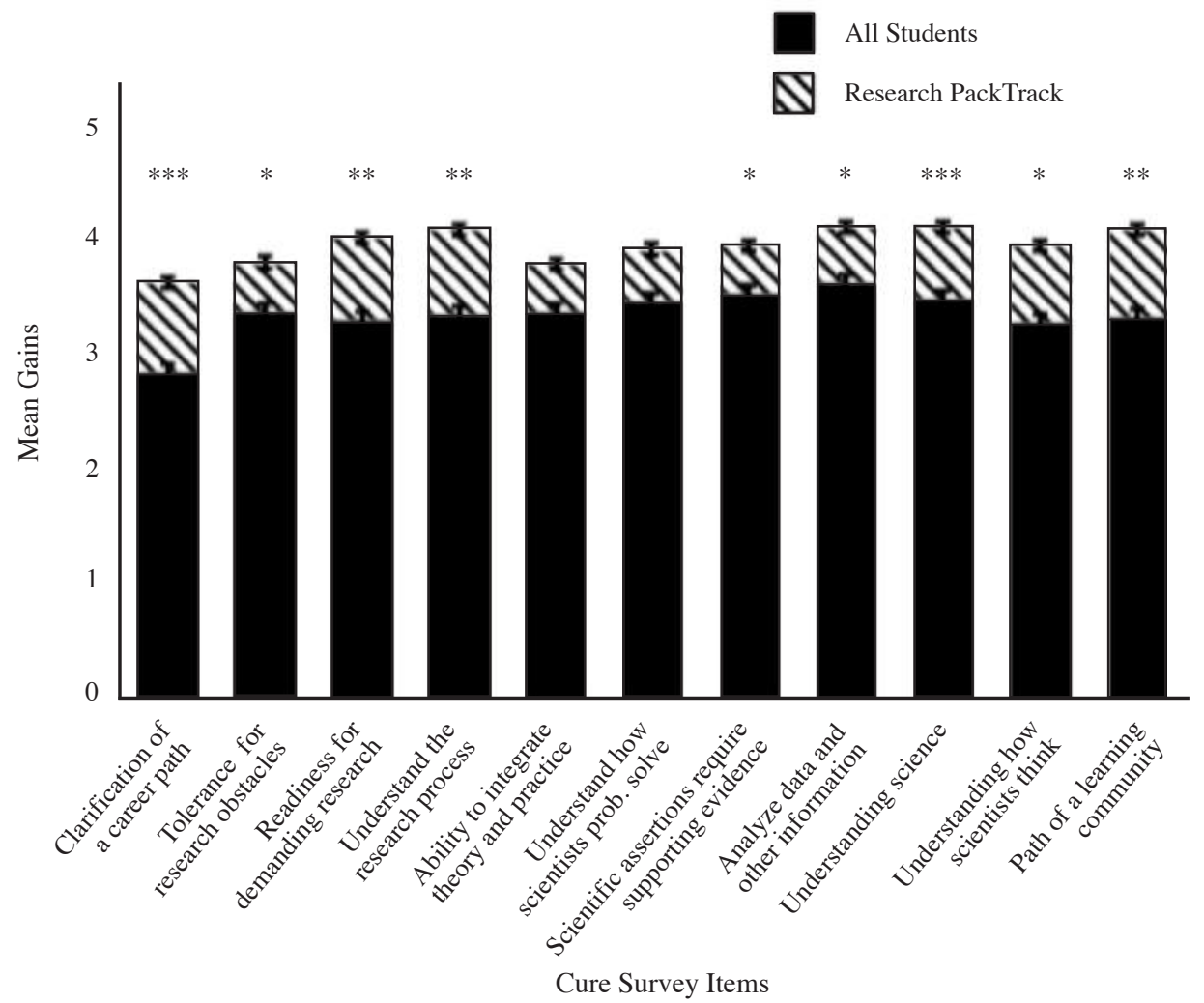

Note: CURE survey data showing learning and self-efficacy gains as related to scientific practice $\left({ }^{*} p \leq 0.05\right.$, $* * p \leq 0.01, * * * p \leq 0.001)$ for all RP students. Solid bars represent all CURE respondents $(n=65,007)$; hatched bars represent Research PackTrack respondents $(n=285)$. For the Y-axis, $1=$ no to very small gain, $5=$ very large gain.

under a specific course category that forms part of the core requirements. Despite some barriers to broad participation, few problems have occurred in recruiting sufficient first-year students as a cohesive cohort to move through the program. However, increasing program flexibility for students with respect to time required for completion and attending to course designation will ensure that a diverse population of students can participate in the RP Program and earn applicable course credit in a timely manner that fits their degree plans.

\section{References}

Beichner, Robert J., and Jeffrey M. Saul. 2003. "Introduction to the SCALE-UP (Student-Centered Activities for Large Enrollment Undergraduate Programs) Project." Proceedings of the International School of Physics "Enrico Fermi," Varenna, Italy, July. https://www.physics.ncsu.edu/physics_ed/Articles/Varenna_SCALEUP_Paper.pdf

Beichner, Robert J., Jeffrey M. Saul, David S. Abbott, Jeanne J. Morse, Duane Deardorff, Rhett J. Allain, Scott W. Bonham, Melissa H. Dancy, and John S. Risley. 2007. "The Student-Centered Activities for Large Enrollment Undergraduate Programs (SCALE-UP) Project." Research-Based Reform of University Physics 1(1): 2-39.

10 Scholarship and Practice of Undergraduate Research
Boyer, Ernest L., and Lee D. Mitgang. 1996. Building Community: A New Future for Architecture Education and Practice. A Special Report. Ewing, NJ: California Princeton Fulfillment Services.

Brooks, D. Christopher. 2012. "Space and Consequences: The Impact of Different Formal Learning Spaces on Instructor and Student Behavior." Journal of Learning Spaces 1(2). http:// libjournal.uncg.edu/jls/article/view/285/275

Clinton, Gregory, and Lloyd P. Rieber. 2010. “The Studio Experience at the University of Georgia: An Example of Constructionist Learning for Adults." Educational Technology Research and Development 58: 755-780. doi: 10.1007/s11423-010-9165-2

Kolb, David A. 1984. Experiential Learning: Experience as the Source of Learning and Development. Englewood Cliffs, NJ. Prentice-Hall.

Lippincott, Joan. 2009. "Learning Spaces: Involving Faculty to Improve Pedagogy.” Educause Review 44(2): 16-25.

Lopatto, David. 2004. "Survey of Undergraduate Research Experiences (SURE): First Findings." Cell Biology Education 3: 270-277. doi: 10.1187/cbe.04-07-0045

Park, Elisa L., and Bo Keum Choi. 2014. "Transformation of Classroom Spaces: Traditional Versus Active Learning 
Classroom in Colleges." Higher Education 68: 749-771. doi: 10.1007/s10734-014-9742-0

Taylor, Summer Smith. 2009. "Effects of Studio Space on Teaching and Learning: Preliminary Findings from Two Case Studies." Innovative Higher Education 33: 217-228. doi: 10.1007/s10755008-9079-7

Tom, Jim S. C., Kenneth Voss, and Christopher Scheetz. 2008. "The Space Is the Message: First Assessment of a Learning Studio." Educause Quarterly 31(2): 42-52.

\section{Mary Beth Hawkins}

North Carolina State University,

beth_hawkins@ncsu.edu

Mary Beth Hawkins is a teaching assistant professor in the Department of Biological Sciences at NCSU. Co-creator of Research PackTrack, she directs the planning and implementation of student research modules for the program. Her scientific research focuses on the functional evolution of estrogen receptors and endocrine disruption in teleost fishes. She is also a dedicated educator who is passionate about introducing young people to the creative world of life science research and has mentored more than 100 students in research projects over the past seven years. She is a National Academies Education Fellow in the life sciences and has received numerous Thank a Teacher awards from the NCSU student body. In addition to directing the Research PackTrack Program, Hawkins also teaches human physiology and comparative physiology at the undergraduate and graduate levels.

Miriam Ferzli is a teaching associate professor and Alumni Distinguished Undergraduate Professor in the Department of Biological Sciences at NCSU. She also co-directs the Research PackTrack Program. She teaches large lecture introductory biology courses for biology majors and the SCALE-UP version. As part of these roles, Ferzli became involved with GTA Teaching professional development. Her areas of research include self-efficacy in undergraduate research programs, GTA stages of development, writing to learn, and student intrinsic motivation in science. She is also a member of the NC State Academy of Outstanding Teachers and a National Academies Education Fellow.

Lisa Paciulli is a lecturer in the Department of Biological Sciences at NCSU. She teaches Introductory Biology I as well as Research I and Research II in the RP Program. For Research II, her students collect data on the responses of lemurs to novel objects at the Duke Lemur Center. Paciulli has invited undergraduates to coauthor more than 25 publications, including abstracts, encyclopedia articles, book chapters, and journal articles.

\section{Creating Collaborative Connections in and} through Undergraduate Research

\section{CUR Conference 2018 Hyatt Regency Crystal City, VA}

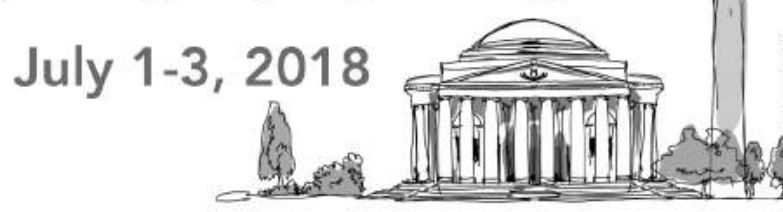

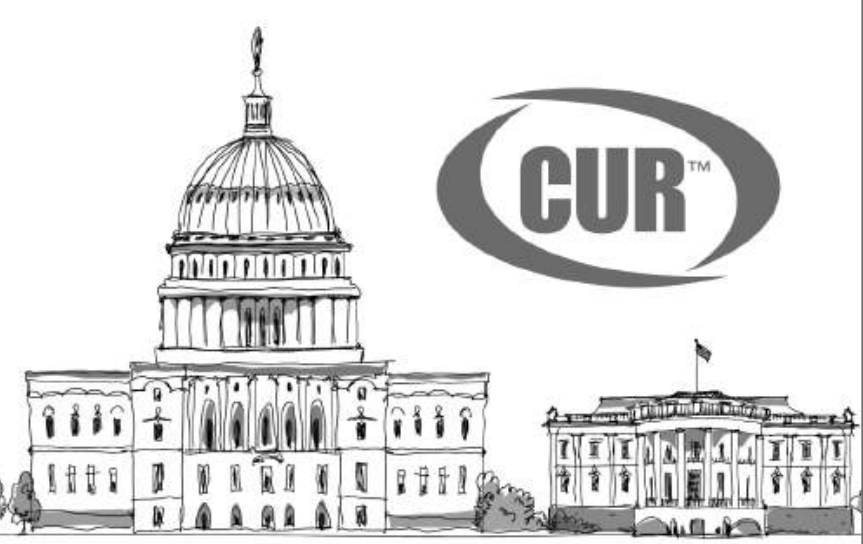

For more information about the CUR Conference, please visit: http://bit.ly/2018CURBiennial 